\title{
PENGEMBANGAN MEDIA PEMBELAJARAN DAN LEMBARAN KERJA SISWA PADA MATERI GAYA DAN USAHA-ENERGI BERBASIS PERALATAN BUDAYA LOKAL PADA MATA PELAJARAN IPA FISIKA SMP
}

\author{
Fakhruddin $Z^{1)}$, Yennita ${ }^{2)}$, Hendar Sudrajad ${ }^{3)}$ \\ ${ }^{1,2,3)}$ Program Studi Pendidikan Fisika FKIP, Universitas Riau \\ e-mail: faruqfisika@yahoo.com
}

\begin{abstract}
Abstrak
Tujuan penelitian ini adalah untuk menguji validitas alat percobaan dan Lembar Kerja Siswa yang dihasilkan dari penelitian yang berbasis peralatan budaya tradisional pada topik gaya, hukum newton dan usaha-energi. Metode penelitian yang digunakan adalah penelitian dan pengembangan atau Reseacrh and Development. Penelitian ini dilaksanakan di laboratorium pendidikan fisika PMIPA FKIP Universitas Riau dengan subjek penelitian media percobaan berbasis peralatan budaya tradisional pada topik gaya, hukum newton serta usaha dan energi dengan sumber data 3 orang pakar pendidikan fisika dan dua guru senior sebagai validator Adapun analisis data yang digunakan adalah analisis deskriptif yaitu mengkategorikan skor rata-rata validitas dari alat percobaan dan lembar kerja siswa pada materi gaya, hukum newton dan usaha-energi berbasis peralatan budaya tradisional. Berdasarkan analisis data hasil penelitian diperoleh skor rata-rata dengan kategori baik dan sangat baik, baik untuk validitas alat percobaan maupun untuk lembar kerja siswa untuk semua aspek yang dinilai. Hal ini menunjukkan alat percobaan dan lembar kerja siswa berbasis peralatan budaya tradisional valid dan dapat digunakan sebagai alat percobaan dan lembar kerja siswa fisika SMP.
\end{abstract}

Kata Kunci: alat percobaan, budaya tradisional, Lembar Kerja Siswa, validasi

\begin{abstract}
The purpose of this study was to examine the validity of experimental tools and student worksheets resulting from research based on traditional cultural tools on the topic of force, newton's law, work and energy. The research method used is research and development or Reseacrh and Development. This research was conducted in physics education laboratory of PMIPA FKIP University of Riau with the subject of experiment media research based on traditional culture equipment on the topic of force, newton's law, work and energy with data source three physics education experts and two senior teachers as validator. The data analysis used is descriptive analysis that categorizes the average validity scores of experimental tools and student worksheets on force, newton's laws, work and energy based of traditional cultural equipment. Based on data analysis, the research results obtained the average score with good category and very good, both for the validity of the experimental tool and for the student worksheet for all aspects. It shows experimental tools and student worksheets based on traditional cultural tools are valid and can be used as experimental tools and worksheets of junior physics students.
\end{abstract}

Keywords: experimental tools, traditional culture, student worksheets, validation 


\section{Pendahuluan}

Fisika adalah bagian sains yang mempelajari cara mencari tahu tentang alam secara sistematis, sehingga sains bukan hanya penguasaan kumpulan pengetahuan yang berupa fakta-fakta, konsep-konsep, atau prinsip-prinsip saja tetapi juga merupakan suatu proses penemuan. Oleh karena itu pendidikan sains harus menekankan pada pemberian pengalaman langsung untuk mengembangkan kompetensi agar siswa mampu menjelajahi dan memahami alam sekitar secara ilmiah. Pendidikan Sains diarahkan untuk "mencari tahu" dan "berbuat" sehingga dapat membantu siswa untuk memperoleh pemahaman yang lebih mendalam tentang alam sekitar (Permendik nas, 2006).

Sudah menjadi pendapat umum bahwa fisika merupakan salah satu pelajaran yang kurang diminati (Afrizal Mayub, 2005). Salah satu penyebabnya adalah fisika banyak mempunyai konsep yang bersifat abstrak sehingga sulit membayangkannya. Oleh sebab itu, banyak siswa yang langsung saja bekerja dengan rumus-rumus fisika, tanpa mencoba berusaha untuk mempelajari latar belakang falsafah yang mendasarinya. Bila saja konsep-konsep yang bersifat abstrak itu dapat dibuat menjadi nyata sehingga mudah ditangkap oleh pancaindra, maka masalahnya akan sangat berbeda, untuk itu diperlukan media pembelajaran.

Kesalahpahaman konsep pada siswa yang wujud secara terus-menerus dapat mengganggu pembentukan konsepsi ilmiah. Menurut Luchembe et al. (2014) Pemahaman yang tepat dari konsep yang dipahami oleh siswa sangat penting untuk pembelajaran konsep-konsep ilmiah lainnya. Pembelajaran yang tidak memperhatikan kesalahpahaman konsep menyebabkan kesulitan belajar dan akhirnya akan menyebabkan rendahnya hasil belajar siswa. Menurut Ephias \& Tawanda (2014) kesalahpahaman pelajar terhadap konsep sains mengungkapkan bahwa kesalahpahaman ini memiliki fitur-fitur umum seperti siswa sering sangat tahan terhadap pembelajaran tradisional. Pembelajaran tradisional yang menganggap bahawa penge tahuan boleh dipindahkan secara menyeluruh dari pikiran guru kepada pikiran siswa perlu diubah menuju pandangan konstruktivisme yang beranggapan bahawa pengetahuan dibina didalam diri pelajar (kablan \& Kaya, 2014).

Peneliti pendidikan fisika telah menunjukkan bahwa siswa memiliki beberapa kesulitan dan miskonsepsi pada konsep fisika dalam mekanika diantaranya pada materi Gaya (Semih, 2015). Kajian yang lain tentang pemahaman siswa terhadap konsep fisika menunjukkan bahwa banyak siswa memiliki miskonsepsi pada berbagai konsep yang merupakan dasar bagi pengetahuan mendalam tentang fisika; seperti saat ini diakui secara luas bahwa miskonsepsi pelajar dalam fisika yang menghambat pemahaman pelajar (Chee, 2010; Simanek, 2008). Kesalahpahaman yang sama terjadi, mulai dari tingkatan rendah sampai pada tingkatan universitas. Hal ini menunjukkan bahwa proses pengajaran dan pembelajaran konvensional atau tradisional tidak dapat mengatasi miskonsepsi jika fokus pengajaran adalah tidak ditargetkan pada miskonsepsi (Erol et al., 2015).

Media pembelajaran sangat membantu dalam proses pembelajaran fisika dengan fungsi memperjelas bahan pelajaran yang sedang diajarkan (Yuliandari, 2012; Sukarno \& Sutarman, 2014). Anita (2009). Menyatakan bahwa, "Media Pembelajaran memiliki banyak jenis dan tidak ada satupun media yang paling baik dibandingkan dengan media yang lain. Setiap media memiliki keunggulan dan kelemahan masing-masing" Guru dapat memilih dan menggunakan media yang sesuai dengan kompetensi dasar, karak teristik siswa serta materi yang akan disampaikan. Keberhasilan menggunakan media pembelajaran yang dikemukakan oleh Sutjiono pada jurnal pendidikan sebagai berikut: Keberhasilan menggunakan media dalam proses pembelajaran untuk meningkat kan hasil belajar tergantung pada (1) isi pesan, (2) cara menjelaskan pesan dan (3) karakteristik penerima pesan. Tidak berarti bahwa semakin canggih media yang digunakan akan semakin tinggi hasil belajar atau sebaliknya. Media pembelajaran yang sederhana lebih efektif dan lebih efesien jika dikemas dengan tepat serta disajikan kepada siswa yang tepat pula.

Salah satu pembelajaran bersifat kontekstual adalah pembelajaran berbasis budaya. Pembelajaran berasas budaya merupakan strategi penciptaan lingkungan belajar dan perancangan pengalaman belajar 
yang mengintegrasikan budaya sebagai bagian dari proses pembelajaran (Dirjen Dikti, 2004). Pembelajaran berbasis budaya dilandaskan pada pengakuan terhadap budaya sebagai bahagian yang fundamental bagi pendidikan, ekspresi dan komunikasi suatu gagasan, serta perkembangan pengetahuan. pembelajaran mengintegrasikan budaya lokal dalam proses pembelajaran bukan saja dapat meningkatkan hasil belajar, namun bisa juga meningkatkan apresiasi terhadap budaya Tradisional/lokal (Morales, 2014; Malaluan \& Masangcay, 2015).

Berdasarkan uraian tersebut, peneliti menyadari akan perlunya mengembangkan media pembelajaran fisika berbasis budaya lokal Riau, dengan demikian penulis ber maksud membuat penelitian dengan judul "Pengembangan Media Pembelajaran dan Lembaran Kerja Siswa pada Materi Gaya dan Usaha-Energi Berbasis Budaya Lokal pada Mata Pelajaran IPA Fisika SMP, rumusan masalah dalam penelitian ini adalah "Bagai mana Pengembangan Media Pembelajaran dan Lembaran Kerja Siswa pada Materi Gaya, Usaha-Energi Berbasis Budaya Lokal pada Mata Pelajaran IPA Fisika SMP.

Tujuan penelitian adalah untuk 1) merancang media pembelajaran pada materi Gaya, Usaha-Energi dan Lembaran Kerja Siswa berbasis budaya Lokal pada mata pelajaran IPA Fisika SMP yang layak digunakan dalam pembelajaran, 2) Membuat dan menguji media pembelajaran pada Materi Gaya, Usaha-Energi berbasis budaya Lokal pada mata pelajaran IPA Fisika SMP yang layak digunakan dalam pembelajaran dan 3) Membuat dan menguji Lembaran Kerja Siswa pada materi Gaya, Usaha-Energi berbasis budaya lokal pada mata pelajaran IPA Fisika SMP yang layak digunakan dalam pembelajaran. Kontribusi yang diharapkan dari penelitian ini adalah untuk menyediakan media pembelajaran dan Lembaran Kerja Siswa pada materi Gaya dan Usaha-Energi berbasis peralatan budaya lokal yang layak digunakan di Sekolah Menengah Pertama, adapun teori yang mendasari penelitian ini adalah media pembelajaran, pembelajaran kontekstual, dan pembelajaran berbasis budaya lokal.

\section{Media Pembelajaran}

Kata media berasal dari bahasa Latin dan merupakan bentuk jamak dari kata medium yang secara harfiah berarti perantara atau pengantar. Dalam bahasa Arab, media adalah perantara atau pengantar pesan dari pengirim kepada penerima pesan (Sardiman, 2011). Media adalah suatu alat yang mempunyai fungsi menyampaikan pesan.

Arsyad (2007) mengatakan bahwa media pendidikan alat bantu pada proses belajar baik di dalam maupun di luar kelas dalam rangka komunikasi antara guru dan siswa dalam proses pembelajaran. Dari beberapa pengertian media tersebut maka dapat disimpulkan bahwa media itu bisa berbentuk softwere maupun hardware dan sebagai alat bantu proses belajar mengajar baik di dalam kelas maupun di luar kelas yang berfungsi sebagai menyalurkan pesan yang dapat merangsang pikiran, perasaan, perhatian dan kemauan siswa sehingga dapat mendorong terjadinya proses belajar pada diri siswa.

Media pendidikan adalah sebuah alat yang berfungsi untuk menyampaikan pesan pembelajaran. Pembelajaran adalah sebuah proses komunikasi antara pembelajar, pengajar dan bahan ajar. Komunikasi tidak akan berjalan tanpa bantuan sarana penyampai pesan atau media (Rusman, 2012).

Ashyar (2012), menyampaikan bahwa: 1). media pembelajaran dapat memberikan maklumat yang tepat. 2). Media Pembelajaran dapat menambah gaya tarik materi, sehingga dapat meningkatkan motivasi dan kecenderungan tersebut. kemudian dapat mengambil perhatian pelajar untuk fokus pada mengikuti materi yang disampaikan, sehingga juga diharapkan belajar secara efektif akan mengalami peningkatan. 3). Media boleh merangsang pelajar untuk berfikir kritis, menggunakan imaginasi mereka, mempunyai sikap dan lebih jauh dikembangkan, sehingga akan menghasilkan kreativitas dan karya inovatif. Sitanggang (2013) menyebutkan bahwa media atau alat peraga adalah sebahagian dari media pembelajaran yang didefinisikan sebagai semua objek (boleh berupa benda manusia atau mati, objek) sebagai perantara yang digunakan dalam proses pembelajaran.

\section{Pembelajaran Kontekstual}

Jonhson (2012) menerangkan bahwa pendekatan kontekstual adalah pendekatan yang membolehkan pelajar mampu menghubungkan isi dari subjek-subjek 
akademik dengan konteks kehidupan seharian mereka dalam mencari makna. Sebagai sebuah pendekatan pembelajaran, pendekatan kontekstual mem-punyai tujuh komponen yang perlu dikembangkan oleh guru diantarannya, (1) kontruktivisme, (2) mencari (inquiry), (3) bertanya (questioning), (4) masyarakat belajar (learning community), (5) pemodelan (modelling), (6) refleksi (reflection), dan (7) penilaian sebenarnya (authentic assessment) (Rusman, 2012).

Istiqomah, Lailatul (2009) menyampaikan pembelajaran kontekstual merupa kan konsep belajar yang membantu guru mengait kan antara materi pembelajaran dengan situasi dunia nyata siswa dan mendorong siswa membuat hubungan antara pengetahuan yang dimilikinya dengan penerapannya dalam kehidupan mereka sehari-hari. Dari uraian tersebut, dapat disimpulkan bahwa pembelajaran dengan pendekatan kontekstual memberikan penekanan pada penggunaan berpikir tingkat tinggi, transfer pengetahuan, permodelan, informasi dan data dari berbagai sumber.

Pendekatan berasaskan konteks bertujuan untuk mengembangkan dan mempertahankan rasa kagum dan ingin tahu pada pelajar tentang dunia alam. Pendekatan berasaskan kontekstual bertujuan untuk mengembangkan dan mempertahankan rasa kagum dan ingin tahu tentang alam (Eser \& Neslihan, 2014). Pada masa yang sama, konteks boleh membantu pelajar untuk menghubungkan pengetahuan saintifik dengan kehidupan nyata (Laguador, 2014; Korganci et al, 2015; Hasruddin et al, 2015). Para siswa diperlukan untuk mendorong makna dengan menggunakan konteks, sehingga membenar kan "keperluan-untuk-tahu" pendekatan kandungan (Yigit, 2010). Dengan demikian, minat dan sikap positif pelajar terhadap fisika telah meningkat (Eser ÜLTAY, 2014).

\section{Pembelajaran Berbasis Budaya Lokal}

Pembelajaran berbasis budaya merupakan strategi penciptaan lingkungan belajar dan perancangan pengalaman belajar yang mengintegrasikan budaya sebagai bagian dari proses pembelajaran. (Dirjen Dikti, 2004). Pembelajaran berbasis budaya dilandaskan pada pengakuan terhadap budaya sebagai bagian yang fundamental bagi pendidikan, ekspresi dan komunikasi suatu gagasan, serta perkembangan pengetahuan.

Belajar melalui budaya merupakan strategi yang memberikan kesempatan siswa untuk menunjukkan pencapaian pemahaman atau makna yang diciptakannya dalam suatu mata pelajaran melalui ragam perwujudan budaya. Belajar melalui budaya merupakan salah satu bentuk multiple representation of learning (Dirjen Dikti, 2004), atau bentuk penilaian pemahaman dalam beragam bentuk. Belajar dengan budaya meliputi pemanfaatan beragam bentuk perwujudan budaya. Menurut Adhitama et al. (2015) Dalam belajar dengan budaya, budaya dan perwujudannya menjadi media pembelajaran dalam proses belajar, menjadi konteks dari contoh-contoh tentang konsep atau prinsip dalam suatu mata pelajaran, serta menjadi konteks penerapan prinsip atau prosedur dalam suatu mata pelajaran. Tentunya pembelajaran dengan menggunakan budaya sebagai perwujudan media sangat berkesan untuk membuat pelajar faham akan pelajarannya (Jasni \& Zulikha, 2013)

Provinsi Riau banyak sekali memiliki peralatan yang digunakan dalam budaya lokal, misalnya, kilangan, gelek, penumbuk padi, kisaran, pengusir burung, pemeras santan, budaya-budaya lokal lainnya. Semua alat-alat dan budaya ini yang dulunya merupakan alat dan budaya yang dapat mempersatukan masyarakat dalam sistem ekonomi pada saat itu. Setelah dicermati alatalat ini sangat kental dengan konsep-konsep fisika, dengan alat-alat ini bisa mempermudah penanaman konsep fisika pada siswa.

\section{Bahan dan Metode}

Penelitian ini dilakukan di Laboratorium Pendidikan Fisika jurusan PMIPA FKIP Universitas Riau, Tahun Ajaran 2016/2017. Penelitian dilakukan mulai Juli sampai November Tahun 2016. Sedangkan jenis penelitian yang digunakan adalah pengembangan R\&D (Research \& develop ment). Penelitian $\mathrm{R} \& \mathrm{D}$ digunakan untuk menghasilkan produk tertentu atau menyempurnakan yang sudah ada (Sugiyono, 2012).

Berdasarkan pengembangan R\&D (Research \& Development), peneliti melaku 
kan prosedur percobaan seperti Gambar 1. Objek penelitian mengenai pengembangan perangkat percobaan. Perangkat media pembelajaran fisika yang dikembangkan dalam penelitian ini terdiri atas tujuh komponen dari alat percobaan dan Lembaran Kerja Siswa.

Instrumen penelitian yang dikembang kan dalam penelitian ini adalah berupa angket validasi instrumen alat percobaan dan lembar kerja siswa dengan menggunakan skala Likert. Instrumen pengumpulan data meliputi:

\section{Validasi}

Validitas suatu instrumen penelitian adalah derajat yang menunjukkan dimana suatu tes mengukur apa yang hendak diukur, suatu tes yang diukur bersifat valid tidak universal.

1. Lembar penilaian alat percobaan

Penilaian alat percobaan meliputi, keberfungsian, ukuran, kontruksi, kemudahan penggunaan, keamanan penggunaan, ketepatan sebagai alat percobaan, nilai ekonomis, nilai edukatif dan psikologi, estetika, dan nilai budayanya.
2. Lembar penilaian Lembar Kerja Siswa Lembar penilaian isi buku panduan mencakup :

1. Konsep yang dikembangkan sesuai dengan tuntutann kurikulum

2. Konsep yang dikembangkan sesuai dengan tuntutan kompetensi dasar

3. Materi praktikan sesuai dengan konsep pelajaran

4. Prosedur kerja sesuai dengan alat peraga

5. instruksi-instruksi cukup jelas dan dapat dipahami.

Teknik pengumpulan data dilakukan menggunakan sumber primer dengan kuesioner validasi. Kuesioner (angket) validitas instrumen penilaian alat percobaan dan Lembaran Kerja Siswa yang dilakukan oleh 3 orang pakar Fisika di Universitas Riau dan 2 orang guru Fisika setelah peneliti melakukan peragaan percobaan.

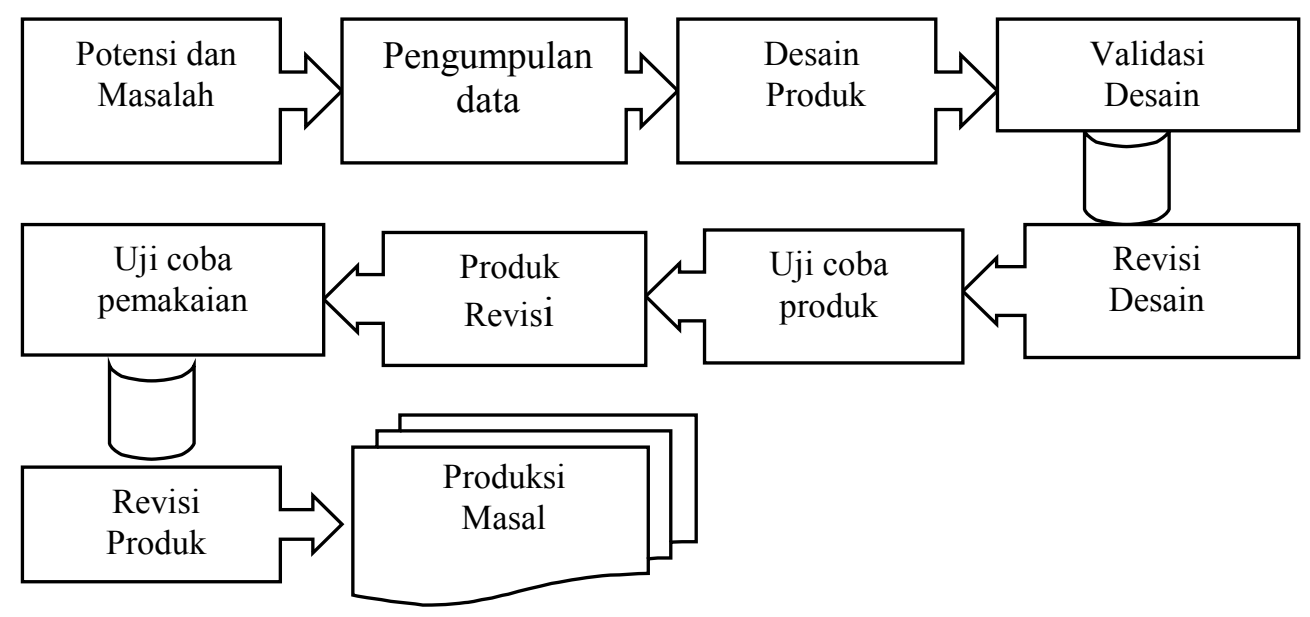

Gambar 1. Diagram Alur Prosedur Penelitian

Teknik analisis data yang digunakan pada penelitian ini adalah analisis deskriptif. Analisis deskriptif terhadap data untuk variabel-variabel sebuah penelitian mencakup penggambaran hasil penelitian yang berupa mean, penyimpangan standar, dan jarak antara angka terendah dan tertinggi (Creswell, 2010).

$$
\text { Analisis data hasil validasi }
$$
menggunakan kategori menurut Tabel 1 dan Tabel 2 dengan langkah-langkah sebagai berikut dengan: 
Tabel 1 Kategori penilaian angket

\begin{tabular}{clc}
\hline No & \multicolumn{1}{c}{ Kategori } & Skor \\
\hline 1 & Sangat Baik & 5 \\
2 & Baik & 4 \\
3 & Cukup & 3 \\
4 & Kurang Baik & 2 \\
5 & Sangat Kurang Baik & 1 \\
\hline
\end{tabular}

1. Menjumlahkan tiap indikator angket validasi.

2. Mencari rata-rata tiap indikator angket validasi.

3. Mencari rata-rata keseluruhan angket validasi.

4. Menentukan kategori rata-rata indikator berdasarkan Tabel 1 dengan menggunakan skala Likert.

Kategori validasi dapat dilihat seperti Tabel 2.
Tabel 2 Kategori validasi

\begin{tabular}{clc}
\hline No & \multicolumn{1}{c}{ Kategori } & $\begin{array}{c}\text { Rentang Skor } \\
\text { Rata-rata }\end{array}$ \\
\hline 1 & Sangat baik & $4,2 \leq \bar{x}<5,0$ \\
2 & Tinggi & $3,4 \leq \bar{x}<4,2$ \\
3 & Cukup & $2,6 \leq \bar{x}<3,4$ \\
4 & Rendah & $1,8 \leq \bar{x}<2,6$ \\
5 & Sangat Rendah & $1,00 \leq \bar{x}<1,8$ \\
\hline \multicolumn{2}{l}{ Sumber: (Muhammad Isnaini Kasipahune, 2013) }
\end{tabular}

\section{Hasil dan Pembahasan}

Berdasarkan hasil penelitian, alat percobaan berbasis peralatan budaya tradisional dinyatakan valid. Dari Tabel 3 diperoleh ketujuh media pembelajaran pada kategori baik dan sangat baik,

Tabel 3. Validitas alat percobaan

\begin{tabular}{llrrrrrrrr}
\hline & & \multicolumn{10}{c}{ ALAT PERCOBAAN } \\
\cline { 3 - 10 } No & Validitas & A & B & C & D & E & F & G & RT \\
& Rata-rata & 4.64 & 4.8 & 4.66 & 4.72 & 4.74 & 4.82 & 4.74 & 4,72 \\
\multirow{1}{*}{$\mathbf{1}$} & Kategori & B & SB & B & SB & SB & SB & SB & SB \\
\hline
\end{tabular}

Tabel 4. Validitas LKS

\begin{tabular}{lclrrrrrrr}
\hline No & & \multicolumn{10}{c}{ LKS } \\
\cline { 3 - 11 } & Praktikalitas & A & B & C & D & E & F & G & RT \\
& Rata-rata & 4.64 & 4.72 & 4.64 & 4.56 & 4.72 & 4.68 & 4.72 & 4.65 \\
$\mathbf{1}$ & Kategori & B & SB & B & B & SB & B & SB & B \\
\hline
\end{tabular}

Keterangan:
A.Mengukur Gaya
B. Gaya gesekan
C. Gesekan gaya sentuh
D. Gaya Berat
E. Hukum Newton
F. Identifikasi energi kinetik dan potensial
G.Menemukan Konsep Usaha energi 
Alat ini sudah melalui tahap validasi sebanyak dua kali dengan beberapa kali perbaikan sesuai dengan saran yang diberikan oleh validator, ada beberapa saran dari validator antara lain

1. Perbaikan mengenai ukuran alat, dimana ukuran alat masih dinilai belum proporsional oleh validator.

2. Keamanan dalam penggunaan juga mendapat tanggapan dari validator, sebaiknya tidak ada bagian alat percobaan yang tajam dan runcing.

3. Nilai estetika juga diperlukan dalam mendesain alat percobaan, sebaiknya alat percobaan dibuat semenarik mungkin sehingga menimbulkan motivasi dari siswa.

Hasil penilaian alat menunjukkan bahwa seluruh alat peraga telah valid mencakup validitas isi (keberfungsian dan ketepatan sebagai alat percobaan, serta nilai kebudayaan) dan validitas konstruk (ukuran, kontruksi dan estetika). Dengan kategori nilai sangat baik Artinya alat peraga yang dibuat telah valid dan mampu menunjukkan gejala fisis dari konsep gaya, hukum newton dan usaha-energi.

Media pembelajaran sebelum digunakan harus valid. Hal ini sesuai dengan pernyataan Sugiono 2014, validitas bertujuan mengukur ketepatan instrumen yang digunakan, artinya media yang digunakan dapat mengukur apa yang diukur secara tepat dan benar.

Media pembelajaran yang digunakan untuk menunjang pembelajaran tidak hanya valid tetapi juga harus praktis. Menurut Nana Sudjana (2007) media pembelajaran yang praktis adalah media pembelajaran yang jelas sehingga mudah dipahami siswa, memberikan pengalaman belajar yang nyata dan dapat menumbuhkan kegiatan berusaha sendiri pada setiap anak.

Ada beberapa hal yang harus diketahui pada alat percobaan yang dikembangkan yaitu:

a. Alat percobaan sudah berupa alat utuh yang dirangkai, alat dapat langsung digunakan untuk percobaan. Sehingga tidak memerlukan waktu yang lama untuk merangkai alat. Syaiful Bahri (2006) mengungkapkan bahwa salah satu faktor yang perlu dipertimbangkan dalam memilih alat bantu adalah efisiensi yakni dalam menggunakan media waktu, tenaga dan biaya yang dikeluarkan sedikit mungkin.

b. Alat percobaan mudah digunakan oleh siswa. Siswa dapat melakukan percobaan secara mandiri dengan dituntun oleh lembar kerja siswa. Alat percobaan tidak perlu dirangkai oleh siswa sehingga mudah digunakan. Salisa Nun Shiha (2014) menyatakan bahwa pemanfaatan alat peraga pada mata pelajaran fisika dapat membuat siswa belajar dengan mendapatkan pengalaman langsung dan membangun pemahaman dengan sendiri nya. Selain itu melalui kegiatan praktikum dapat melatihkan kemampuan melalui pendekatan ilmiah yang meliputi, mengamati, menanya, mencoba, mengo lah, dan aspek keterampilan lainnya.

c. Perangkat percobaan ini berbasis pada budaya tradisional yang ada di Riau. Sebagian siswa telah mengenal alat tersebut dalam bentuk yang nyata. Ketika siswa melihat alat peraga ini sebagian besar telah mengetahui cara menggunakan alat ini sehingga dengan alat ini terjadilah pembelajaran kontekstual. Pembelajaran berbasis budaya dilandaskan pada pengakuan terhadap budaya sebagai bahagian yang fundamental bagi pendidi kan, ekspresi dan komunikasi suatu gagasan, serta perkembangan pengetahuan. pembelajaran mengintegrasi kan budaya tempatan dalam proses pembelajaran bukan saja dapat meningkatkan hasil belajar namun bisa juga meningkatkan apresiasi terhadap budaya Tradisional/ lokal (Morales, 2014; Malaluan \& Masangcay, 2015).

d. Alat percobaan dibuat dalam ukuran yang proporsional. Tidak terlalu kecil untuk dijadikan sebagai alat percobaan. Serta tidak terlalu besar untuk dipindahkan dan disimpan. Alat juga dapat disimpan di dalam lemari atau juga dapat dipajang.

e. Alat percobaan ini terbuat dari bahan yang tahan terhadap benturan ringan. Benturan yang dimaksud disini bukan merupakan benturan yang kuat melainkan benturan ringan hingga sedang. Sehingga alat ini tidak mudah pecah dan aman digunakan oleh siswa. 
Penilaian LKS mencakup validitas isi dan validitas kontruk. Validitas isi dan validitas kontruk juga melalui dua tahap validasi. Pada validasi pertama, validator memberikan saran agar foto alat peraga \& cover LKS diperbaiki lagi agar terlihat menarik. Hasil penilaian ini menunjukkan bahwa konsep dalam LKS dan tahapantahapan percobaan dapat membantu siswa dalam memahami konsep gaya, hukum Newton dan usaha-energi.

Pada tahap pertama validasi, validasi konstruk LKS belum dinyatakan valid dan terdapat beberapa saran dari validator. Berdasarkan saran tersebut dilakukan perbai kan, sehingga validitas konstruk dapat dinyata kan valid. Artinya LKS telah dapat menimbulkan ketertarikan kepada siswa untuk mempelajari dan memahami konsep gaya, hukum newton dan usaha-energi.

\section{Kesimpulan dan Saran}

Berdasarkan data yang telah dikumpulkan dan analisis data pada pembahasan yang telah diuraikan, maka dapat disimpulkan bahwa alat percobaan dan Lembar Kerja Siswa pada matari gaya, hokum newton dan usaha energi dinyatakan, hal ini mengacuh pada tingkat kategori media berada pada kategori baik dan sangat baik untuk semua aspek penilaian. Perangkat percobaan ini telah teruji validitas sehingga dapat digunakan sebagai perangkat percobaan dan Lembar Kerja Siswa dalam pembelajaran fisika SMP pada topik Gaya, Hukum Newton dan usahaenergi.

Berdasarkan simpulan yang diperoleh penulis merekomendasikan guru untuk menguji kepraktisannya dan selanjutnya dapat menggunakannya dalam proses pembelajaran di sekolah.

\section{Daftar Pustaka}

Adhitama, E., Nur Aini, A \& Widarwati, G. 2015.. "Wayang Saintis" The Learning Media Based On Culture As An Illustration Of Scientist For Physics Teaching. 15th Indonesian Scholars International Convention, London.
Anita, S., 2009. Media Pembelajaran. UNS Press. Surakarta.

Arsyad, A., 2007. Media Pembelajaran. Raja Grafindo Persada, Jakarta.

Ashyar, R., 2012. Kreatif Mengembangkan Media Pembelajaran. Referensi, Jakarta.

Chee, T. C., 2010. Common Misconceptions in Frictional Force among Univer sity.

Creswell, John., 2010, Research Design Pendekatan Kualitatif, Kuantitatif dan Mixed, Pustaka Pelajar, Yogyakarta.

Dirjen Dikti, 2004. Pedoman Pengintegrasian Pembelajaran Berbasis Budaya dalam Pembelajaran.

Ephias, G \& Tawanda, M., 2014. Pedago gics of chemical bonding in Chemistry; perspectives and potential for progress: The case of Zimbabwe secondary education. International Journal of Secondary Education 2(1):11-19. Zimbabwe.

Erol, T., et al., 2015. The effects of classic and web-designed conceptual change texts on the subject of water chemistry. International Electronic Journal of Elementary Education 7(2): 263-280. Turkey.

Eser ÜLTAY, 2014. Context-Based Physics Studies: A Thematic Review of the Literature. Journal of Education. Giresun, Turkey,

Eser, U. \& Neslihan, U., 2014. Context-Based Physics Studies: A Thematic Review of the Literature. Hacettepe Üniversitesi Eğitim Fakültesi Dergisi (H. U. Journal of Education) 29(3): 197-219.

Jasni, A \& Zulikha, J., 2013. Utilising Wayang Kulit for Deep-Learning in Mathe matics. Proceedings of the World Congress on Engineering 2013 Vol II: London.

Jonhson, Elaine B., 2012. Contextual Teaching and Learning: Menjadikan Kegiatan Belajar Mengajar Mengasyikkan dan Bermakna. Kaifa. Bandung.

Kablan, Z \& kaya, S. 2014. Preservice Teachers' Constructivist Teaching Scores Based on Their Learning Styles. Australian Journal of Teacher Educa tion 3(12): 66-76. Kocaeli University.

Lagaudor, J., M., 2014. Cooperative Learning Approach In An Outcomes-Based Environment. International Journal of 
Social Sciences, Arts and Humanities 2(2): 46-55. Philippines.

Luchembe, D. et al., 2014. The Effect of Using Concept Mapping on Student's Attitude and Achievement When Learning the Physics Topic of Circular and Rotational Motion. European $J$ of Physics Educa tion 5(4): 10 - 29. Zambia.

Malauluan, N., E \& Masancay, D., B., 2015. Physics Instruction Utilizing CultureBased Pedagogy. Asia Pacific Journal of Multidisciplinary Research 3(4): 5058. Batangas State University.

Mayub, Afrizal, 2005. e-Learning Fisika Berbasis Macromedia Flash MX. Penerbit Graha Ilmu, Yogyakarta.

Morales, M., P., E., 2014. The Impact of Culture and Language Sensitive Physics on Concept Attainment. International Journal of Learning, Teaching and Educational Research 2(1):1-29. Philippine Normal University.

Permendikbud, 2006. Peraturan Menteri Pendidikan Nasional Nomor 22 Tahun 2006, tentang standar isi.

Nana Sudjana, 2007. Dasar-dasar Proses Belajar Mengajar. Sinar Baru, Bandung.

Rusman, 2012. Model-Model Pembelajaran Mengembangkan Profesionalisme Guru. PT Raja Grafindo Persada, Jakarta.

Salisa Nun Shiha, 2014. Pengembangan Alat Peraga Percepatan Benda untuk Menunjang Pembelajaran Fisika Pada Materi Hukum Newton Tentang Gerak. Jurnal Inovasi Pendidikan Fisika (JIPF). ISSN: 2302-4496 Vol. 3(2): 180-184.
Semih DALAKLIOĞLU, Neşet DE MİRCİ, AyşeGül ŞEKERCIOĞLU. 2015. Eleventh Grade Students' Difficulties and Misconception about Energy and Momentum Concepts International Journal on New Trends in Education and Inter national Journal on New Trends in Education and Their Implications. January 2015 Volume: 6 Issue: 1 Article: 02 ISSN 1309-6249.

Simanek, D. E., 2008. Student Misconcep tions Induced By Teachers and Textbook.

Sitanggang, Ahmadi, 2013. Alat Peraga Matematika Sederhana untuk Sekolah Dasar, Sumatera Utara: Lembaga Penjaminan Mutu Pendidikan.

Sugiyono, 2014. Metode Penelitian Pendidikan, pendekatan kuantitatif kualitatif dan R\&D. Alfabeta, Bandung.

Sukarno \& Sutarman, 2014. The Development of Light Reflection Props As A Physics Learning Media In Vocational High School Number 6 Tanjung Jabung Timur. Inter national Journal of Innovation and Scientific Research 12(2): 346-355. Indonesia.

Syaiful Bahri Djamarah dan Aswan Zain, 2006. Strategi Belajar Mengajar. Rineka Cipta, Jakarta.

Yigit, N., 2010. Developing presentation skills of student teachers through microteaching method. Energy Education Science and Technology Part B: Social and Educational Studies, 2, 55-74.

Yuliandari, Karina, 2012. Media sebagai Alat bantu Pengajaran Fisika. Universitas Ahmad Dahlan, Yogyakarta. 